\title{
Relationship between Immunosuppressive Medications Adherence and Quality of Life and Some Patient Factors in Renal Transplant Patients in Iran
}

\author{
Maryam Shabany Hamedan ${ }^{1} \&$ Jaleh Mohamad Aliha ${ }^{1}$ \\ ${ }^{1}$ School of Nursing and Midwifery, Department of Medical Surgical Nursing, Iran University of Medical \\ Science, Tehran, Iran \\ Correspondence: Jaleh Mohammad Aliha, MSC, School of Nursing and Midwifery, Department of Medical \\ Surgical Nursing, Iran University of Medical Science, Tehran, Iran. Tel: 98-21-8888-2885. Fax: \\ 98-21-8820-1978. E-mail: mohammadaliha.j@iums.ac.ir
}

Received: January 23, 2014

Accepted: March 12, 2014 Online Published: April 16, 2014

doi:10.5539/gjhs.v6n4p205

URL: http://dx.doi.org/10.5539/gjhs.v6n4p205

\begin{abstract}
Background \& Aim: About organ transplant, immunosuppressive medications adherence is a critical issue, because non-adherence to these medications causes rejection, reduces quality of life and increases treatment cost and mortality rate. Among these, the quality of life is deemed very important to evaluate treatment result and also it can be useful for discovering non adherence. The aim this study was to assess the relationship between medication adherence and quality of life and some patient factors in renal transplant patients.

Methods: The study was a descriptive-correlational design and was done on renal transplant patients over 18 who had undergone surgery for over 3 months, and were inclined to participate. Sample size was 230 people and sampling was convenience. Quality of life questionnaire in renal transplant patients and Immunosuppressant Therapy Adherence Scale were filled by patients and the data was analyzed by SPSS15 software.

Results: It showed that the mean score of quality of life in renal transplant patients was $21.65 \pm 4.03$ and $57.8 \%$ of them did not adhere to immunosuppressive medications. Results of correlation between scores of immunosuppressive medication adherence and Quality of life showed that there were significant correlation in 3 dimensions of 4 : health performance $(p \leq 0.0001 \&$ rETA=0.23), social-economic $(p=0.001$ \& rETA=0.15), psychological-spiritual $(\mathrm{p}=0.011 \& \mathrm{rETA}=0.15)$, also logistic test showed significant relationship between immunosuppressive medication adherence and number of transplantation $(\beta=1.04, p=0.048)$.
\end{abstract}

Conclusion: According to the results, health care providers i.e. nurses must note to medication adherence as a health enhancement factor while treating and educating to these patients.

Keywords: medication adherence, immune - system suppressors, quality of life, renal transplant

\section{Background}

Nowadays, renal transplant is a satisfying and proven method of treating advanced chronic kidney diseases. There has been tens of thousands of transplants in the world and in some centers, 50 to 100 kidney transplant operations are performed annually (Fauci et al., 2008). In Iran, the kidney transplant rate is 24 per million which is 1-5 per million in developing countries and 20-40 per million in advanced countries. Iran with over 20,000 annual operations ranks $1^{\text {st }}$ in the region (Support Association of Kidney Patients online, 2007).

Renal transplant releases the patient from many restrictions of dialysis (Rambod, Shabany-Hamedan, Shokrpour, Rafii, \& Mohammad alliha, 2011) but is not the final treatment of kidney anomaly. This operation is in fact a follow-up of treatment with its own side-effects and potential impacts (Phipps, Neighbors, \& Green, 2007). Survival after transplant emphasizes adherence to immunosuppressive therapy (Kugler et al., 2007).

The powerful combination of immunosuppressive therapy gives excellent short-term results and guarantees transplant acceptance with little potential of acute rejection (Hansen, Seifeldin, \& Noe, 2007; Massey et al., 2013). It is very clear that advantage of medication regimen is realized when patient makes logical and precise use of prescription (Marcén, 2009; Osterberg \& Evert Koop, 2005).

The renal transplant receivers must follow the immunosuppressive medication regimen for a long time so the 
rejection is prevented and mortality is reduced. Therefore a high degree of adherence to immunosuppressive therapy is essential (Denharynck \& Belgien, 2006).

Non adherence to immunosuppressive therapy is an important issue in renal transplant patients. Almost $20 \%$ of renal transplant patients do not adhere to these groups of medications. The non adherence involvement in transplant rejection is $16 \%$ and in acute rejection is $20 \%$ (Osterberg \& Evert Koop, 2005). Also past research showed there are defects in adherence to immune -suppressor system intake in receivers of the organ. Instead of dangers caused by non adherence, $20-25 \%$ of adults who receive heart, liver $\&$ kidney transplant do not adhere to adherence to their body immunosuppressive therapy and it is and finally this will lead to reduced quality of life. Also, the side -effects of using immunosuppressive therapy affect various aspects of life (Mann, 2004). Measuring quality of life in clinical studies makes patient feel more intimate to the doctor and health service providers. This makes patient aware of their disease and the conditions that lead to health, getting acquainted to advantages \& disadvantages of various treatment and emphasizing the patient role in choosing treatment method (Donlad, 2003).

Measuring quality of life toget access to essential statistics for policy-making and planning has many applications in social / clinical goals (Donlad, 2003). Since on one side, it is vital to take clinical decisions for the needy person and on the other, in taking social decisions for planning and following a policy (Molnar-Varga, 2011). Here, the nurses are very effective in implementing strategy for improving adherence since they are present in all healthcare scenes and intimacy with the people. They can ask patient about consumed drugs, their effect on their quality of life and identifying \& educating patients who do not adhere to their immune - system suppressors, can prevent transplant defect of even patient death (Fredericks et al., 2008).

\section{Materials \& Methods}

This study was a descriptive correlational designand was conducted to assess the relationship between immunosuppressive medication adherence and quality of life in renal transplant patients.

The study population consisted of all transplant patients with over 3 months after transplant and over 18 years. The sample size at $90 \%$ reliability was 230 persons . The research samples were selected consistently (convenience) from among research population, i.e. all qualified patients with the required capacity participated in the research. Sampling took 2.5 months. Sample exclusion criteria were people with mental/bodily disabilities, transplantpatients who had less than three months. The research was down at the council of advocacy of renal disorder patients and its affiliate treatment clinic.

For assessing immunosuppressive medication adherence was used of Immunosuppressant Therapy Adherence Scale (ITAS). In this questionnaire, 12 score means full adherence and below that means non adherence. This tool was designed based on Likert 4-options scale with 4 questions (in the last 3 months how often did you: forgot to take their immunosuppressant therapy or IST medications, careless about taking their IST medications, stopped taking their IST medications because they felt worse, and missed taking their IST medications for any reason) and is matched with selecting the appropriate option by the patient. The options are never $=3$, seldom $=2$, often $=1$, always $=0$.

Patient selects one option based on the way he/she adherence to immunosuppressive medication.

The criteria for immunosuppressant therapy adherence is 12 , i.e. the person must select never to be considered adhered.Toclarifythe reasons of non-adherence in the last question, researcher listed some of them and patients were asked to check mark them. Questionnaire may be filled in 3-5 minutes.

The second questionnaire relates to the quality of life in renal transplant patients and it is composed of 2 sections: satisfaction \& importance. Each section has 35 questions and each question is scored relative to its rating. The questionnaire is rated by 6 -options Likert type scale in the first section as $6=$ very satisfied to $1=$ very dissatisfied and in the second section as $1=$ very unimportant to $6=$ very important. The 2 sections have similar statements. This tool measured 4 dimensions in quality of life: health/performance, socioeconomics, psychological/spiritual, family. The questionnaire was applied as interview or as filled by the person (self-report) and takes 15 minutes. Validity of both tools was determined through formal content validity method. So that after translating questionnaires from English to Persian and again back to English and removing any back-translated distortion, 10 experts of Midwifery \& Nursing Faculty of Iran Medical Science University, checked and verified this tool. The internal consistency of the questionnaire for adherence to immunosuppressive therapy was calculated through Coefficient Alfa $=0.78$. This tool was calculated by Chisholm et al. (2005) using Coefficient Alfa $=0.81$. Also, the reliability of the questionnaire for quality of life was calculated through Coefficient Alfa $=0.8$ and this tool was calculated by France \& Powers using Coefficient Alfa $=0.9$ :

The researcher began the study after obtaining the permit of Iran Midwifery \& Nursing Faculty Ethical Committee. 
At first, the researcher attended the council of advocacy of renal disorder patients and its affiliate treatment clinic and after full explanation of research goals and emphasis on confidentiality and obtaining written consent, collected the samples. Two questionnaires of adherence to medication and quality of life in renal transplant patients were completed by the samples. To answer research questions, the Chi-Square and Logistics Regression was used relative to application.

\section{Results}

Data was analyzed by SPSS15 software and showed that the meanparticipants age was 41.69 years $(\mathrm{SD}=12.174)$ with min age 18 and max age 68. The frequency percentage of men and women was respectively 55.2 and 44.8 . The most frequency of marital status in both sexes was for married individuals $(72.2 \%)$ and the least was for the divorced (4.3\%). Most of the participants had intermediate degree (28.7\%) and minorities were in university level (10.4\%). Highest frequency distribution of occupational status was among housewives (34.8\%) and least among students $(0.9 \%)$. Most participants were of economic middle class $(50.6 \%)$ and a few were of higher class $(3.5 \%)$. Most patients were urban (88.7\%) and some (10.9\%) were living in rural areas. The most frequency of length of time for using immunosuppressive therapy (time since the transplant) was 5.00 years $(\mathrm{SD}=3.9)$ and the most frequency type of immunosuppressive medication regimen was Cellcept-Sandimmune(cyclosporine)-Prednisone $(76.52 \%)$ and the least was monotherapy regimen that is, only Cellcept $(0.4 \%)$.

Also based on number of prescribed medications by practitioner, the most frequency was 3-medications (88.7\%), and the least was 1 medication $(0.4 \%)$. Most of the patients $(66.5 \%)$ citedthat used other medications except immunosuppressive medications (for example: Medications for hypertension, hyperlipidemia, seizures and anti depressant and so on), also they had forgot number, type and name of other medications and did not say precisely. and the most frequency of the number of using immunosuppressive therapyper day was 2 times (71.7) and the least was 3 times (11.3). The mean number of using immunosuppressive therapy per day was 2.45 times (SD $=0.768)$. The most frequency of transplant operation was first time operation ( $90 \%)$. Most frequency of donor types was alive-stranger (93\%) and the least was alive-family (2.6\%). Most frequency of distribution of chronic disease was related to no disease option equal to $39.6 \%$. Most frequency of distribution of chronic disease type was hypertension (47.96\%) and then diabetes (14.47\%) and the least was related to other disease (colic, asthma, G6PD, lupus) equal to $1.8 \%$. Most patients were non adherence $(57.8)$ and mean score of quality of life was 21.65( $\mathrm{SD}=4.03)$.most of the patients had disireble quality of life $(71.3 \%)$.

In assessing the relationshipbetween adherence to immunosuppressant medication therapy with some of the more relevant parametersprobably, it was revealed that adherence has significant relation with age $\left(p=0.049, X^{2}=8.873\right)$, The time since transplant $\left(p=0.041, X^{2}=9.948\right)$ and the number of renal transplant $\left(p=0.036, X^{2}=4.376\right)($ Table 1$)$ Since the frequency distribution is based on the adherence and non-adherence, the sum of percentages adjusted horizontally. Because there is no space and vertical table seemed more appropriate here. Also Table 2 shows that most percentage (sum of percentage) related to non adherence is for question one that is forgot to take the immunosuppressive medications and for other reasons following the response to question 4, price of medication is more than the others.

Logistics correlation test showed that Adherence is more related to the number of transplant $(B=1.041, p=0 / 048)$ (Table 3). Also there is significant relationship between medication adherence and quality of life ( $\mathrm{p} \leq 0.0001$, $\left.\mathrm{X}^{2}=12.204\right)$ and with health \& life performance life $\left(\mathrm{p} \leq 0.0001, \mathrm{X}^{2}=12.189\right)$, and with socioeconomic aspect of quality of life $\left(\mathrm{p}=0.003, \mathrm{X}^{2}=11.322\right)$, and with psychological \& spiritual dimension life $\left(\mathrm{p}=0.017, \mathrm{X}^{2}=5.669\right)$.

Todetermine which of dimensions hasmore closely correlation with adherence was used of correlation coefficient ETA.

Results of correlationbetween immunosuppressive medication adherence and Quality of life in this patients shows that there were significant correlation in 3 dimensions of 4 : health performance $(p \leq 0.0001 \&$ rETA=0.23), social-economic $(\mathrm{p}=0.001 \& \mathrm{rETA}=0.15)$, psychological- spiritual $(\mathrm{p}=0.011 \& \mathrm{rETA}=0.15)$

Medication adherence is most of all related to health /performance dimension life (Table 4). 
Table 1. Relationship between adherence and variables

\begin{tabular}{|c|c|c|c|c|c|c|}
\hline \multirow{2}{*}{$\begin{array}{l}\text { Adherence immunosuppressive drug } \\
\text { variables }\end{array}$} & \multicolumn{2}{|c|}{ Adherence } & \multicolumn{2}{|c|}{ Non adherence } & \multicolumn{2}{|c|}{ Chi-Square statistic } \\
\hline & $\mathrm{N}$ & $\%$ & $\mathrm{~N}$ & $\%$ & $\left(X^{2}\right)$ & $\mathrm{P}$ \\
\hline \multicolumn{7}{|l|}{ Age } \\
\hline $30 \geq$ & 19 & $40 / 4$ & 28 & $59 / 6$ & $7 / 87$ & $0 / 049 *$ \\
\hline $31-40$ & 29 & 18 & 44 & 71 & & \\
\hline $41-50$ & 34 & $53 / 1$ & 30 & $46 / 9$ & & \\
\hline $51 \leq$ & 26 & $45 / 6$ & 31 & $54 / 4$ & & \\
\hline \multicolumn{7}{|l|}{ Sex } \\
\hline Woman & 41 & $39 / 8$ & 62 & $60 / 2$ & $0 / 42$ & $0 / 51$ \\
\hline Man & 56 & $44 / 1$ & 71 & $55 / 9$ & & \\
\hline \multicolumn{7}{|l|}{ Marital status } \\
\hline Single & 13 & $33 / 3$ & 26 & $66 / 7$ & $3 / 25$ & $0 / 35$ \\
\hline Married & 73 & 44 & 93 & 56 & & \\
\hline Divorced & 6 & 60 & 4 & 40 & & \\
\hline Widowed & 5 & $33 / 3$ & 10 & $66 / 7$ & & \\
\hline \multicolumn{7}{|l|}{ Occupational status } \\
\hline Employed & 34 & $45 / 3$ & 41 & $54 / 7$ & & \\
\hline Pension & 19 & $48 / 7$ & 20 & $51 / 3$ & & \\
\hline Unemployed & 14 & $41 / 2$ & 20 & $58 / 8$ & & \\
\hline Housewife/men & 29 & $36 / 3$ & 51 & $63 / 8$ & & \\
\hline Student & 1 & 50 & 1 & 50 & $2 / 20$ & $0 / 45$ \\
\hline \multicolumn{7}{|l|}{ Educational level } \\
\hline Illiterate & 12 & $38 / 7$ & 19 & $61 / 3$ & & \\
\hline Elementary & 25 & $39 / 1$ & 39 & $60 / 9$ & & \\
\hline Secondary & 18 & 40 & 27 & 60 & & \\
\hline Intermediate & 34 & $51 / 5$ & 32 & $48 / 5$ & & \\
\hline University \& higher & 8 & $31 / 3$ & 16 & $68 / 7$ & $3 / 62$ & $0 / 45$ \\
\hline \multicolumn{7}{|l|}{ Frequency ofmedication useduring the day } \\
\hline 2 & 71 & 43 & 94 & 57 & & \\
\hline 3 & 12 & $46 / 2$ & 14 & $53 / 8$ & & \\
\hline$\geq 4$ & 14 & $35 / 9$ & 25 & $64 / 1$ & $0 / 84$ & $0 / 65$ \\
\hline \multicolumn{7}{|l|}{ Economical status } \\
\hline Poor & 51 & 48.1 & 55 & 51.9 & & \\
\hline Fair & 43 & 37.1 & 73 & 62.9 & & \\
\hline Good & 3 & 37.5 & 5 & 62.5 & 2.84 & 0.09 \\
\hline \multicolumn{7}{|l|}{ The time since transplant } \\
\hline$\leq 1$ & 20 & $57 / 1$ & 15 & $42 / 9$ & & \\
\hline $2-5$ & 46 & $37 / 7$ & 76 & $62 / 3$ & & \\
\hline $6-9$ & 21 & $46 / 7$ & 24 & $53 / 3$ & & \\
\hline $10-15$ & 10 & $47 / 6$ & 11 & $52 / 4$ & & \\
\hline $16-21$ & 0 & 0 & 100 & 7 & 9/94 & $0 / 041^{*}$ \\
\hline \multicolumn{7}{|c|}{ Type of immunosuppressive medication regimen } \\
\hline Cyclosporine-cellcept- Prednisone & 71 & $40 / 3$ & 105 & $59 / 7$ & & \\
\hline Azathioporine-Cyclosporine-Prednisone & 17 & $51 / 5$ & 16 & $48 / 5$ & & \\
\hline Prednisone -Cyclosporine & 2 & $28 / 6$ & 5 & $71 / 4$ & & \\
\hline Cyclosporine- Cellcept & 6 & $46 / 2$ & 7 & $53 / 8$ & & \\
\hline Cellcept & 1 & 100 & 0 & 0 & $1 / 42$ & $0 / 49$ \\
\hline \multicolumn{7}{|c|}{ Number of prescribed immunosuppressive medications } \\
\hline 1 & 1 & 100 & 0 & $0 * *$ & & \\
\hline 2 & 10 & 42.3 & 15 & 57.7 & & \\
\hline
\end{tabular}




\begin{tabular}{|c|c|c|c|c|c|c|}
\hline \multirow{2}{*}{$\begin{array}{l}\text { Adherence immunosuppressive drug } \\
\text { variables }\end{array}$} & \multicolumn{2}{|c|}{ Adherence } & \multicolumn{2}{|c|}{ Non adherence } & \multicolumn{2}{|c|}{ Chi-Square statistic } \\
\hline & $\mathrm{N}$ & $\%$ & $\mathrm{~N}$ & $\%$ & $\left(X^{2}\right)$ & $\mathrm{P}$ \\
\hline 3 & 86 & 42.2 & 118 & 57.8 & 0.0 & 0.99 \\
\hline \multicolumn{7}{|c|}{ number of using immunosuppressive therapy per day } \\
\hline 2 & 71 & 43 & 94 & 57 & & \\
\hline 3 & 12 & 46.2 & 14 & 53.8 & & \\
\hline$\geq 4$ & 14 & 35.9 & 25 & 64.1 & 0.84 & 0.65 \\
\hline \multicolumn{7}{|l|}{ Chronic disease } \\
\hline yes & 59 & 64.9 & 80 & 87.8 & & \\
\hline No & 38 & 41.8 & 53 & 58.2 & 0.619 & 0.89 \\
\hline \multicolumn{7}{|l|}{ Number of transplant } \\
\hline First transplant & 92 & $44 / 4$ & 115 & $21 / 7$ & $4 / 37$ & $0 / 036^{*}$ \\
\hline Second transplant & 5 & $55 / 6$ & 18 & $87 / 3$ & & \\
\hline \multicolumn{7}{|l|}{ Type of transplant } \\
\hline alive-familiar & 2 & $33 / 3$ & 4 & $66 / 7$ & & \\
\hline alive-strange & 93 & $43 / 5$ & 121 & 56 & & \\
\hline Cadaver & 2 & 20 & 8 & 80 & $2 / 08$ & $0 / 149$ \\
\hline \multicolumn{7}{|l|}{ Quality of life } \\
\hline Relatively desirable & 16 & $16 / 5$ & 50 & $37 / 6$ & & \\
\hline desirable & 81 & $83 / 5$ & 83 & $62 / 4$ & $12 / 20$ & $*<0 / 0001$ \\
\hline
\end{tabular}

*There is significant relationship**2columnsof one $\&$ two medications merged for Chi-square test.

Table 2. Reason for non-adherence

\begin{tabular}{|c|c|c|c|c|}
\hline Reason for non-adherence & Never(3) & $\operatorname{Seldom}(2)$ & Often(1) & Always(0) \\
\hline \multicolumn{5}{|l|}{ Immunosuppressant Therapy Adherence Scale } \\
\hline 1-forgot to take & $138(60 \%)$ & $56(24.3 \%)$ & $26(11.3 \%)$ & $10(4.3 \%)$ \\
\hline 2-careless about taking & $144(62.6 \%)$ & $51(22.2 \%)$ & $28(12.2 \%)$ & $7(3 \%)$ \\
\hline 3 -stop taking to feeling worse & $209(90.9 \%)$ & $5(2.2 \%)$ & $11(4.8 \%)$ & $5(2.2 \%)$ \\
\hline 4-Missed taking for any reason & $197(85.7 \%)$ & $16(7 \%)$ & $13(5.7 \%)$ & $4(1.7 \%)$ \\
\hline Other reasons following the response to question 4: & $\mathbf{N}$ & $\%$ & $\checkmark$ & \\
\hline Price of medication & 11 & 33.33 & $33^{*}$ & \\
\hline Running out of medication & 5 & 15.15 & & \\
\hline Difficult scheduling medication & 4 & 12.12 & & \\
\hline Taking around food & 1 & 3.03 & & \\
\hline no having choose to take it & 2 & 6.07 & & \\
\hline Too many medication to take & 3 & 9.09 & & \\
\hline Misplaced medication & 5 & 15.15 & & \\
\hline Belief that medication is not working & 2 & 6.06 & & \\
\hline Sum & 33 & 100 & & \\
\hline
\end{tabular}

* Sum of responses of patients that shows non-adherence with other reason.

Table 3. Logistic correlation test

\begin{tabular}{lllll}
\hline variable & B & df & p- value & $\mathbf{E x p ( B )}$ \\
\hline Age & $0 / 017$ & 1 & $0 / 16$ & $0 / 98$ \\
Since time of transplant & $0 / 04$ & 1 & $0 / 28$ & $1 / 041$ \\
number of kidney transplant & $1 / 04$ & 1 & $0 / 048^{*}$ & $2 / 83$ \\
\hline
\end{tabular}

*It shows that adherenceandnumberof kidneytransplant have more relationship. 
Table 4. Relationship between adherence and dimension's quality of life

\begin{tabular}{lll}
\hline Adherence Quality Of life & rETA & p-value \\
\hline health - performance & $0 / 23$ & $0 / 0001^{*}$ \\
economic - social & $0 / 15$ & $0 / 001$ \\
psychological - spiritual & $0 / 15$ & $0 / 011$ \\
family & $0 / 18$ & $0 / 42$ \\
\hline
\end{tabular}

*It shows that adherence and health - performance havemore relationship.

\section{Discussion}

Study finding shows there is significant relationship between immunosuppressive medication adherences (ITAS score) and the age of transplant patients with 41-50 age groups .according to Table 1, they had the highest adherence. This finding is similar to study of Greenstein and Seagull (1998). They found that elders have more adherence to immunosuppressive therapy relative to younger ones. Furthermore Weng et al. (2013) in therir research found this results, median age 55 (in years) had adherence.

Also, adherence is more related to the time since transplant, i.e. most percentage of adherence is for patients with less than 1 year after transplant and the highest non adherence was among patients whose transplant operation dated back to $16-21$ years ago. This was similar to Greenstein \& Seagull study. They found that the more time passes after renal transplant, medication adherence is less probable. It seems that with increasing age of transplant, stress and fatigue occurs in the individual because of continuous follow-ups and as a result the patient would not cooperate to regular medication intake. However, Butler et al. (2004) study did not show any significant relationship between these two variables. Also Burk halter et al. (2014) study showed that Younger age and more years since transplantation were associated with higher non adherence.

Also, there is a significant relation between the number of renal transplant and medication adherence. Present study shows that the people who received their second renal transplant were more non adherence. Percentages in Table 1 points to more adherences to immunosuppressive therapy in first transplant relative to second transplant. Presumably, in patients who are under transplant surgery for the first time are more persistent than patients who have lost kidney in first time of transplant for any reason (including non adherence) Also, medication adherence is related to quality of life in renal transplant patients. In this study according to the result, it seemed adherence has affected on the quality of life because most of the patients who were adherence, had desirable quality of life so immunosuppressant medication adherence is independent variable and quality of life is dependent (Ortega et al., 2009).

Fredricks et al. (2009) in their study on liver transplant adolescents found significant relation between medication adherence and quality of life and depression score and found that non adherence reduces quality of life. Akman et al. (2007) in a study on patients in the renal transplant operation found a significant difference between adherence \& quality of life score and depression score. They found that non adhering patients, have lower quality of life and more depression scores. Furthermore, Gorevsk's study (2013) showed significant relationship between medication non adherence and quality of life, hence kidney transplant patients' physical functional status was strongly associated with non adherence, and for each point increase in functionality the patients' adherence increased by $4 \%$.

Also, they noted that non adherence during dialysis might be a similar danger factor for post- renal transplant operation period. Komorosky et al. (2007) found significant difference between heart disease patients and their adherence score and after analysis, it was certain that the low number of drugs, high score of social health and low score of depression and anxiety are predictors of better adherence behavior in heart rehabilitation patients (Chisholm, 2005). Thus, by noting the study results, adherence is an important part of treatment $\&$ care that has significant effect on various aspects of quality of life. In this study, more relationship between adherence and health- performance quality of life indicate that immunosuppressive medication adherence have a vital role in improving the performance. Adherence and quality of life have a close relationship and some dimensions are overlap together.

The five dimension related to adherence are social- economic, health care system, condition- related, therapy-related and patient related, so improvement of this 5 dimensions can be helpful and increase medication adherence and ultimately quality of life (Sabate, 2003).

It is suggested that adherence to immunosuppressive therapy should be converted as an essential training in care of 
these patients. In this study, some patients may have be failure to accept to non adherence or may have problems in recalls so it was better confirmed adherence by serum creatinine concentration .Because of the lack of easy access to patient'slab results therefore it did not.

It is suggested that another research under the same topic should be conducted on heart transplant patients and another one with this same title on a larger sample size.

\subsection{Limitations}

One limitation of our study was that it took place in a single center, though patients were drawn from a variety of ethnic groups and socioeconomic backgrounds, we could not sample from different center because in Tehran there is only one the council of advocacy of renal disorder patients and it was very difficultto accesssamples and more samples. Second limitation was difficulties in access to blood test (blood concentrations of immunosuppressive medication and blood creatinineincrease the accuracy of the measurement non-adherence from participants). In this study was used questionnaire only.

\subsection{Implications for Nursing and Health Policy}

One of the most important health policies is economic implications. Economic implications of non-adherence are increased treatment and nursing care costs alsohealth outcomes that will occur, are diminished quality of life and finally mortality so primary prevention such as education can be effective in decrease non-adherence.

\section{Conclusion}

There was a significant relationship between immunosuppressive medication adherence and quality of life and some patient factors in renal transplant patients. Thus the nurse must take medication adherence as a health enhancement factor while treating and educating these patients.

\section{Acknowledgements}

The researcher sincerely thanks all personnel of at The Supporting Society for Renal Patients and its affiliate treatment clinic.

\section{References}

Akman, B., Uyar, M., Afsar, B., Sezer, S., Ozdemir, F. N., \& Haberal, M. (2007). Adherence, depression and quality of life in patients on a renal transplantation waiting list. Journal compilation, 10, 1-5.

Burkhalter, H., Wirz-Justice, A., Cajochen, C., Weaver, T. E., Steiger, J., Fehr, T. ... De Geest, S. (2014). Daytime sleepiness in renal transplant recipients is associated with immunosuppressive non-adherence: a cross-sectional, multi-center study. Clin Transplant, 28(1), 58-66. http://dx.doi.org/10.1111/ctr.12279

Butler, J. A., Peveler, R. C., Roderick, P., Smith, P. W., Horne, R., \& Mason, J. C. (2004). Modifiable risk factor for non- adherence to immunosuppressant in renal transplant recipients: a cross-sectional study. Nephrology Dial Transplant Journal, 19(12), 1-10.

Chisholm, M. A., Lance, C. E., \& Mulloy, L. L. (2005). Factors associated with adherence to immunosuppressant therapy (IST) in renal transplant recipients. Am Journal health-Syst Pharm, 62(17), 1775-1781. http://dx.doi.org/10.2146/ajhp040541

Chisholm, M. A., Lance, C. E., Williamson, G. M., \& Mulloy, L. L. (2005). Development and validation of the immunosuppressant therapy adherence instrument (ITAS). Patient education and counseling, 59, 13-20. http://dx.doi.org/10.1016/j.pec.2004.09.003

Denharynck, K. (2006). Explorating risk factor of non-adherence to immunosuppressive medication in kidney transplant recipients: improving methodology \& reorienting research goals. Nephrol Dial Transplant, 1-7.

Donlad, A. (2003). What is quality of life (first ed). Hayward medical communications. Retrieved from http://www.medicine.ox.ac.uk/bandolier/painres/download/whatis/WhatisQOL.pdf

Fauci, A., Braunwald, E., Kasper, D., Hauser, S., Longo, D., Jameson, J. L., \& Loscalzo, J. (2008). Harrison's principles of internal medicine, Disorder of the kidney \& urinary tract (17th ed.). McGraw-Hill Professional.

Fredericks, E. M., Magee, J. C., Opipari-Arrigan, L., Shieck, V., Well, A., \& Lopez, M. J. (2008). Adherence and health-related quality of life in adolescent liver transplant recipients. Pediatric transplantation, 12(3), 289-99. http://dx.doi.org/10.1111/j.1399-3046.2008.00901.x

Fredericks, E. M., Magee, J. C., Opipari-Arrigan, L., Shieck, V., Well, A., \& Lopez, M. J. (2009). Adherence and health - related quality of life in adolescent liver transplant recipients. Pediatric transplantation, 1-9.

Ferrence, C. E., Yarbo, C., frogg, F. M., Goodman, M., \& Groenwall, S. (2000). Quality of life as an outcome of 
cancer care (pp. 243-255). Jones and Bartleth international publisher.

Gorevski, E., Succop, P., Sachdeva, J., Cavanaugh, T. M., Volek, P., Heaton, P., ... Martin-Boone, J. E. (2013). Is there an association between immunosuppressant therapy medication adherence and depression, quality of life and personality traits in the kidney and liver transplant population? Patient Preference and Adherence, 7, 301-7. http://dx.doi.org/10.2147/PPA.S34945

Greenstein, S., \& Siegal, B. (1998). Compliance and noncompliance in patients with a functioning renal transplant: A multicenter study. Transplantation, 66(12), 1718-1726. http://dx.doi.org/10.1097/00007890199812270-00026

Hansen, R., Seifeldin, R., \& Noe, L. (2007). Medication adherence in chronic Disease: Issues in posttransplant immunosuppression. Transplantation proceedings, 39, 1287-1300. http://dx.doi.org/10.1016/j.transproceed. 2007.02.074

Kugler, C., Fischer, S., Gottlieb, J., Tegtbur, U., Welte, T., Goerler, H., ... Strueber, M. (2007). Symptom experience after lung transplantation: impact on quality of life \& adherence: impact on quality of life \& adherence. Clinical Transplantation, 21, 590-596. http://dx.doi.org/10.1111/j.1399-0012.2007.00693.x

Komorovsky, R., Desideri, A., Rozbowsky, P., Sabbadin, D., Celegon, L., \& Gregori, D. (2007). Quality of Life and behavioral compliance in cardiac rehabilitation patiens: a longitudinal survey. International journal of nursing studies, 1016, 1-7.

Mann, R. A. (2004). The Importance of transplant recipients. Transplantation Express Report, 6(4), 1-4.

Marcén, R. (2009). Immunosuppressive drugs in kidney transplantation: impact on patient survival, and incidence of cardiovascular disease, malignancy and infection. Drugs, 69(16), 2227-2243.

Massey, E. K., Tielen, M., Laging, M., Beck, D. K., Khemai, R., van Gelder, T., \& Weimar, W. (2013). The role of goal cognitions, illness perceptions and treatment beliefs in self-reported adherence after kidney transplantation: A cohort study. Journal of Psychosomatic Research, 75(3), 229-234. http://dx.doi.org/10.1016/j.jpsychores.2013.07.006

Molnar-Varga, M., Molnar, M. Z., Szeifert, L., Kovacs, A. Z., Kelemen, A, Becze, A., ... Novak, M. (2011). Health-Related Quality of Life and Clinical Outcomes in Kidney Transplant Recipients. American Journal of Kidney Diseases, 58(3), 444-452. http://dx.doi.org/10.1053/j.ajkd.2011.03.028

Ortega, T., Deulofeu, R., Salamero, P., Roman, A., Masnou, N., Rubio, S., ... Ortega, F.; Y Red Temática de Investigatión en Trasplante. (2009). Health-related quality of life before and after a solid organ transplantation (kidney, liver, and lung) of four Catalonia hospitals. Transplant, 41(6), 2265-2267. http://dx.doi.org/10.1016/j.transproceed.2009.06.175

Osterberg, L. B. T., \& Evert koop, C. (2005). Adherence Medication. The new of England Jornal of Medicine, 353-493.

Phipps, F. M., Neighbors, M., \& Green, C. J. (2007). Medical sergical nursing: Health and Illness perspectives Europe, middle est. and African edition ( $8^{\text {th }}$ ed.).

Rambod, M., Shabany-Hamedan, M., Shokrpour, N., Rafii, F., \& Mohammad alliha, J. (2011). Quality of life of hemodialysis and renal transplantation patients. Health Care Manager, 30(1), 23-8. http://dx.doi.org/10.1097/HCM.0b013e3182078ab6

Sabate, E. (2003). Adherence to long-term therapies: Evidence for action. World health organization, 25. Retrieved from http://whqlibdoc.who.int/publications/2003/9241545992.pdf

Support Association of Kidney Patients online. (2007). Kidney transplantation. Retrieved from http://www.irankf.org/Pages/About.aspx

Weng, F. L., Chandwani, Sh., Kurtyk, K. M., Zacker, Ch., Chisholm-Burn, M. A., \& Demissie, K. (2013). Prevalence and correlates of medication non-adherence among kidney transplant recipients more than 6 months post-transplant: a cross-sectional study. BMC Nephrology, 14, 261. http://dx.doi.org/10.1186/1471-2369-14-261

\section{Copyrights}

Copyright for this article is retained by the author(s), with first publication rights granted to the journal.

This is an open-access article distributed under the terms and conditions of the Creative Commons Attribution license (http://creativecommons.org/licenses/by/3.0/). 